\title{
LA CONSTITUCIÓN ECONÓMICA LIBERAL COMO GARANTÍA DEL LIBRE MERCADO. LOS DERECHOS DE PROPIEDAD PRIVADA Y LIBERTAD DE EMPRESA
}

\author{
Jesús López de Lerma Galán \\ doi: 10.18543/ed-64(1)-2016pp39-60
}

\begin{abstract}
Sumario: 1. InTROdUCiÓN. 2. CONSIDERACIONES GENERALES SOBRE LA CONSTITUCIÓN ECONÓMICA LIBERAL. 3. EL SISTEMA ECONÓMICO EN EL DEBATE CONSTITUCIONAL. 4. ELEMENTOS DIFERENCIADORES DE LA CONSTITUCIÓN ECONÓMICA LIBERAL Y LA CONSTITUCIÓN ECONÓMICA SOCIAL. EL DERECHO DE PROPIEDAD PRIVADA Y LA LIBERTAD DE EMPRESA. 5. VALORACIONES FINALES. 6. BiBLIOGRAFÍA.
\end{abstract}

\section{INTRODUCCIÓN}

La Constitución económica liberal es heredera de la revolución liberal y en consecuencia parte de una separación entre Estado y sociedad, que permita desarrollar la actividad económica. Esto exigía que los poderes públicos no tuvieran control en la economía, y si lo ejercían debía ser muy reducido y en todo caso para garantizar una normativa que permitiera el libre desarrollo del mercado.

En orden a las consideraciones metodológicas de esta investigación hemos de destacar un estudio de la filosofía liberal y su influencia en la economía, que dará lugar el concepto de Constitución económica. Para ello es necesario adentrarse en las implicaciones políticas y sociales a lo largo del siglo XIX, que motivaron el surgimiento del constitucionalismo. El estudio del contexto histórico es de vital importancia para comprender el sustrato sobre el que surge el Derecho Constitucional. 
A ello debemos añadir, toda una serie de valoraciones e interpretaciones sobre el carácter economicista, que se ha generado en la sociedad a partir de los movimientos revolucionarios, así como las relaciones entre la política y el derecho por conformar un sistema de regulación de algunos derechos relacionados en la actividad económica. El derecho de propiedad y el de libertad de empresa, son aspectos que también son objeto de estudio en este texto, al entender que están envueltos de implicaciones políticas y jurídicas, que conforman su desarrollo constitucional.

Este enfoque aspira a determinar los orígenes de la Constitución económica, marcando los elementos de su definición como concepto jurídico, dentro del proceso constitucional. No hay que olvidar, que el movimiento liberal abrió nuevas fórmulas de libertad política, en las que se encontraba implícito el liberalismo en la economía, lo que sirvió para transformar el mundo en el orden social y económico.

\section{CONSIDERACIONES GENERALES SOBRE LA CONSTITUCIÓN ECONÓMICA LIBERAL}

Para entender la influencia del liberalismo en los sistemas económicos debemos analizar su contexto histórico. Los ideales liberales como libertad política, armonía sobre los intereses económicos, libre comercio entre las naciones y laicismo educativo y cultural, determinaron la quiebra del modelo establecido en el Antiguo Régimen. Países como Inglaterra, EE.UU o Francia, experimentan un gran avance y desarrollo durante el siglo XIX ${ }^{1}$. El absolutismo gestado en el Antiguo Régimen perdió su sentido ante los nuevos caminos de renovación que el liberalismo trajo a la sociedad. Un posicionamiento que reclama el papel del individuo como ciudadanos dotado de derechos, conforma una nueva estructura económica que abrirá el libre comercio entre las naciones e impulsará los cánones educativos y culturales a una nueva dimensión, donde la economía tendrá un papel preponderante.

Uno de los argumentos que debemos tener en cuenta en esta investigación reside en la idea de que todo ordenamiento constitucional incorpora una Constitución económica, aunque es difícil identificar esta propuesta en los textos constitucionales que se enmarcan histórica e ideológicamente en la tradición liberal. No podemos negar que, en todos los ordenamientos constitucionales, implícita o explícitamente se da acogida a un conjunto de reglas que disciplina el sistema económico. Todo ello debe ser objeto de matización, así por ejemplo el artículo 17 de la Declaración de Derechos del Hombre y el Ciudadano de 1789, reconoce como derecho inviolable o sagrado la

${ }^{1}$ Bassols Coma, M., Constitución y sistema económico, Editorial Tecnos, Madrid, 1985, p. 24. 
propiedad privada, convirtiéndose en un elemento clave de la Constitución económica burguesa. Por tanto, no se puede mantener que esa ausencia de una Constitución económica formalmente recogida en el texto constitucional supusiera una ausencia de los elementos económicos². La Revolución Francesa surge bajo el signo de conquistar especialmente las libertades políticas frente a la vieja estructura del Antiguo Régimen ${ }^{3}$. Lo más elemental en la formación de la Constitución económica burguesa es la existencia de una serie de principios que si bien no recogían formalmente los parámetros formales de una Constitución económica al menos albergaba la esencia integradora de valores económicos, que posteriormente podrían ser regulados.

Para entender este proceso debemos insistir que el primer constitucionalismo tenía características diferentes en cada Estado, siendo las mismas tributarias de la peculiar historia de cada lugar y de la coyuntura política; pero en esa nueva organización de los poderes del Estado encontramos un contrapeso al monarca ${ }^{4}$. Hay que matizar que si bien los herederos de las revoluciones liberales se fundamentan en las ideas de libertad, igualdad y fraternidad, hay que tener en cuenta que los parlamentos del XIX más que representar una voluntad popular, defendían el interés de la Nación. En ese siglo observamos el crecimiento de sistemas económicos como el capitalista basado en el laissez-faire que incrementó la desigualdad económica de las minorías y el nacimiento del movimiento obrero ${ }^{5}$. Los procesos revolucionarios son factores de cambio y transformaciones de la sociedad y, en esos movimientos, encontramos el desarrollo de los sistemas económicos.

Los valores básicos del Estado democrático-liberal eran la libertad, la propiedad individual, la igualdad, la seguridad jurídica y la participación de la formación de los ciudadanos en la voluntad estatal a través del sufragio. Por tanto, no podemos actualizar la libertad si su establecimiento y garantías formales no van acompañadas de unas condiciones existenciales mínimas que hagan posible su ejercicio. Debemos tener en cuenta que en los si-

${ }^{2}$ Garcia Llovet, E., «Constitución económica y Constitución territorial económica», Autonomías: Revista Catalana de Derecho Público . $^{\circ} 22,1997$, pp. 121-122.

${ }_{3}$ RUIZ JIMÉNEZ, J., «Derechos humanos y estructura socioeconómicas en un régimen constitucional democrático», en VV.AA: Constitución, economía y regiones. Edita Ibérico Europea de Ediciones, Madrid, 1978, p. 209.

${ }^{4}$ DíAz Revorio, F. J., «Cádiz e Iberoamérica: Sobre las influencias medievales y contemporáneas en la Constitución de $1812 \ldots$ y en Iberoamérica», en VV. AA: La Constitución de 1812 y su difusión en Iberoamérica, Edita Tirant Lo Blanch, Valencia, 2012, p. 23.

5 SAnz Arcega, E., «Los consensos económicos-constitucionales: diagnóstico y afanes de la política económica», Papeles de trabajo del Instituto de Estudios Fiscales. Serie economía, $n .^{\circ} 1,2015$, p. 9. 
glos XVIII y XIX se pensaba que la libertad era una exigencia de la dignidad humana. Además, la seguridad formal tiene que ir acompañada de la seguridad material frente a las necesidades económicas permanentes o contingentes a través de instituciones como el salario mínimo o la seguridad en el em$\mathrm{pleo}^{6}$. La libertad construye toda una filosofía para conseguir que el individuo encuentre derechos cuyo reconocimiento le va a permitir participar de una forma más activa en la economía.

En el desarrollo de la ciencia política ha sido determinante la influencia de la filosofía liberal, sobre todo en el paradigma teórico y metodológico, desde una perspectiva normativa. A ello debemos añadir que la filosofía liberal ha sido impulsora del debate y la deliberación, lo que ha permitido cambios institucionales basados en el principio de igualdad, incorporando nuevos actores políticos al proceso de toma de decisiones ${ }^{7}$, con un valor preponderante del ciudadano.

En las formas históricas del capitalismo y el Estado, que darán lugar a la creación y desarrollo de textos constitucionales y se prolongará hasta la formulación de la Constitución económica, tenemos que destacar el modelo clásico que va desde 1800 a 1945 . Un sistema que comienza con la Revolución Francesa y la Revolución Industrial, teniendo como superestructura política más importante el Estado liberal, tendente a asegurar las condiciones externas del mercado. Posteriormente, más directamente relacionado con el periodo de entreguerras a partir de 1945 entraremos en una fase caracterizada en la Europa occidental por la creación de un modelo estatal basado en la economía de mercado pero con marcado arraigo social ${ }^{8}$. El Estado liberal, heredero de las revoluciones liberales, parte de un posicionamiento que teóricamente quiere asegurar las condiciones externas del mercado. Posteriormente, entraremos en fases más propias de un Estado social donde el intervencionismo en el mercado toma forma, dentro de un contexto de garantías sociales.

La exigencia de difundir la luz en la Ilustración garantizó tanto el progreso como una nueva forma de pensar en las ciencias sociales, desarrollando lo que se puede denominar como la ilustrada economía de mercado. Desde esta perspectiva se puede pensar que la economía clásica entregó los términos de referencia empíricos para los sistemas filosóficos del idealismo alemán, influyendo en la comprensión de conceptos como libertad, poder y derecho de

${ }^{6}$ García-Pelayo, M., Las transformaciones del Estado contemporáneo, Editorial Alianza, Madrid, 1977, p. 26.

7 PARra, J. F., «Liberalismo: nuevo institucionalismo y cambio político», Política y Cultura, n. $^{\circ} 24,2005$, p. 32.

${ }^{8}$ Cancio Meliá, J., «La Constitución Económica: Promesas Incumplibles», Revista Jurídica de la Universidad Autónoma de Madrid, $n .^{\circ} 7$ (2002), pp. 52-53. 
autoridad ${ }^{9}$. El liberalismo económico considera el mercado como una institución que regula los intercambios sociales de una manera natural ${ }^{10}$. La influencia de las revoluciones liberales en la formación de textos constitucionales produjo una nueva forma de pensar y un desarrollo de las ciencias sociales, que abren los parámetros de interpretación de criterios económicos a una nueva formulación.

Para entender todo este proceso de transformación, debemos entender que en el Estado democrático burgués los ciudadanos participan a través del proceso electoral en la formación de la voluntad del Estado, centrada en el Parlamento y capitalmente expresada en leyes. En el Estado social a tal actuación por parte de los ciudadanos se unirá el derecho a la participación, más o menos institucionalizada en las prestaciones del Estado, creando un adecuado ambiente económico. Eso supondrá una nueva forma de democracia social y económica ${ }^{11}$. La evolución social se cumple a través del despliegue de las fuerzas productivas, del incremento de autonomía sistémica (poder) y de la transformación de las estructuras normativas ${ }^{12}$. La participación del ciudadano en la vida política, permitió extender esa voluntad del Estado a través de las instituciones, con una clara proyección de activar la economía a través de un proceso más plural y democrático.

El liberalismo económico se ha entendido como una doctrina específica en relación a la organización económica de las sociedades. La economía de mercado constituye la mejor manera de garantizar el crecimiento económico y de mejorar el nivel de vida de la población de una sociedad. Eso ha supuesto que el liberalismo sea una ideología al servicio de la clase social menos favorecida ${ }^{13}$. Y ello es comprensible, ya que está abierto a una evolución natural, según las circunstancias del propio mercado, sin la intervención de otros agentes o controles gubernamentales que pudieran lastrar su libre crecimiento.

Con el curso del tiempo y teniendo en cuenta las coyunturas históricas, observamos que el Derecho constitucional clásico se sustentaba en la praxis del Estado y la sociedad como sistemas distintos pero no separados. La sociedad se consideraba como un sistema autorregulado capaz de producir el me-

9 MestmäCKer, E-J., «Poder, Derecho y Constitución Económica», Estudios Públicos, $n .^{\circ} 3,1981$, pp. 122-125.

${ }^{10}$ De Castro, C.; Pedreño, A., «La Gran Restauración: sociología económica de la crisis global y actualidad de la crítica de Karl Polanyi al liberalismo económico», Áreas. Revista Internacional de Ciencias Sociales, $n .^{\circ} 31,2012$, p. 7.

11 García-Pelayo, M., Las transformaciones del Estado..., op. cit., pp. 38-39.

12 Habermas, J., Legitimationsprobleme im Spätkapitalismus, Ediciones Cátedra, Madrid 1973, p. 26.

${ }^{13}$ De VRoey, M., «El liberalismo económico y la crisis», Lecturas de Economía, n. ${ }^{\circ} 70,2009$, pp. 13-14. 
jor de los órdenes posibles con tal de que el Estado no interfiriera en su funcionamiento y garantizara libertad y seguridad. El modo de relacionarse el Estado con la sociedad era fundamentalmente la legislación. Así la ley se consideraba principalmente como constitutio y no como actio, es decir como creadores de un orden en cuyo marco se desarrollan las acciones de los individuos $^{14}$. La concepción del liberalismo reside en esa determinación que tiene la sociedad para desarrollarse en libertad, sin que el Estado interfiriera. Crear esa atmosfera de seguridad jurídica, demandará crear un orden basado en el imperio de la ley, de ahí se infiere que la relación del individuo con el Estado sea precisamente a través de la legislación, entre la que tiene un papel determinante los textos constitucionales.

Hay diferentes modalidades de adhesión al liberalismo, pues se trata de posiciones normativas referentes a la manera ideal de organizar la sociedad en su dimensión económica. Lógicamente estas concepciones se desarrollaron en una dialéctica entre la evolución histórica y el discurso teórico de los economistas ${ }^{15}$. Por ello, es importante resaltar que el liberalismo describe las diferentes concepciones de organizar a la sociedad, dentro de una actuación económica que carece de juicios de valor, pero que exige un carácter normativo.

En este contexto de formación de la Constitución económica liberal, no podemos obviar que a la nobleza le sucede la burguesía como clase nacional, que desarrolla su cultura caracterizada por el racionalismo, la Ilustración y la unificación del orden jurídico. Además, hay que destacar que tal cultura tiene mayores posibilidades de extensión que las que poseían la cultura caballeresca de la nobleza, lo que implicó un progreso social, en el que tuvo una parte decisiva la acción administrativa del Estado ${ }^{16}$. La burguesía buscó ese ascenso cultural a través de una serie de principios y derechos, que sirven para dotar de contenidos a sus aspiraciones. En esa formación de los textos constitucionales reside gran parte de los elementos, que permitirá al burgués evolucionar como individuo y convertirse en ciudadano.

Si analizamos el contenido mínimo de la Constitución económica, comprobamos que se integra en preceptos constitucionales atinentes al régimen general de los bienes económicos, a la atribución y distribución de los mismos y a las relaciones de los ciudadanos y los poderes públicos, incluyendo la disciplina básica de los procesos de intercambios de los bienes y las reglas de funcionamiento de la institución. Es pues opinión mayoritaria, la doctrina favorable a considerar una aproximación al problema de la intervención de los poderes públicos en la economía, no como un fenómeno

\footnotetext{
${ }^{14}$ García-Pelayo, M., Las transformaciones del Estado..., op. cit., p. 123.

${ }^{15}$ De Vroey, M., «El liberalismo económico...», op. cit., p. 21.

${ }^{16}$ García-Pelayo, M., Las transformaciones del Estado..., op. cit., p. 42.
} 
puntual sino como un proceso connatural a la vida de los poderes públi$\cos ^{17}$. Una situación que choca frontalmente con las primeras manifestaciones económicas en los textos constitucionales, cuyo desarrollo queda todavía muy alejado de los conceptos de Constitución económica, que entrado el siglo $\mathrm{xx}$, se realizaría.

Hay que tener presente en este análisis, que la Constitución económica originaria respondía al modelo liberal, manteniendo una rígida separación entre el Estado y la Sociedad ${ }^{18}$. Los primeros inicios de esa Constitución económica venía influenciada por unos planteamientos alejados a una realidad pragmática de mayor efectividad, que vendría marcado por el devenir de los tiempos y el desarrollo de la sociedad y de los operadores económicos.

La Constitución económica podemos considerarla como una pléyade de disposiciones legales que resume el reparto del poder, con un alcance que se proyecta sobre la esfera política y también en el ámbito de las relaciones económicas de los sujetos. Analizar la economía permite estudiar la coexistencia de diversas cosmovisiones sobre el mercado y su funcionamiento. La concordancia entre el consenso económico-constitucional se apoya fundamentalmente en dos factores principales: el valor normativo efectivo del texto constitucional y la rigidez del modelo económico juridificado ${ }^{19}$. El modelo de Constitución económica liberal planteaba la necesidad de establecer un reparto del poder que formara una serie de normas básicas, que permita desarrollar un marco jurídico fundamental para la estructura y funcionamiento de la economía. Esto sirvió para crear un consenso económico constitucional, que se apoyara sobre la rigidez del modelo económico y la conexión con el valor normativo que ofrece el marco constitucional.

Será en Alemania donde a finales del siglo XIX y principios del XX surge el término "Constitución económica». Un concepto que ignora el propio concepto liberal de Constitución y que responde más a una necesidad económica. Esto nos hace definir la Constitución económica como «conjunto de normas constitucionales que hacen referencia a una estructura y funcionamiento de la actividad económica», entendida como una interpretación restrictiva, puesto que la razón de ser de la Constitución liberal es la economía ${ }^{20}$. No podemos obviar que, partir de posicionamientos conceptuales restrictivos que interpretan la Constitución económica como norma sobre el funcionamiento de la economía, es una forma de limitar la proyección que puede en-

17 Garcia Llovet, E., «Constitución económica...», op. cit., p. 121.

18 García Guerrero, J. L., «Integración económica y reforma constitucional», en VV.AA.: Senado de la República. Visión y análisis comparativo de reformas constitucionales en Iberoamérica, Edita PNUD, Santo Domingo, 2005, p. 136.

19 Sanz Arcega, E., «Los consensos económicos-constitucionales...», op. cit., p. 7.

${ }^{20}$ García Guerrero, J. L., «Integración económica...», op. cit., p. 137. 
contrar en la Constitución liberal, cuya esencia es el desarrollo del individuo $\mathrm{y}$, en consecuencia, de todos los aspectos económicos inherentes a él.

El caso alemán viene marcado por un conjunto de peculiaridades históricas que, especialmente en el periodo final de la Segunda Guerra Mundial, configuraron la Ley Fundamental Alemana como un texto provisional quedando aplazada la determinación constitucional de un modelo económico, lo que permitió un importante desarrollo jurisprudencial. Así, la Ley Fundamental no garantiza ni la neutralidad política económica de los poderes legislativos y ejecutivos, ni tampoco un modelo de economía social de mercado que sólo debe funcionar mediante instrumentos que sean conformes al mismo. Esa neutralidad político-económica de la Ley Fundamental, reside en que el legislador no se ha decelerado de ningún modo expreso a favor de un determinado modelo económico. Además, esa neutralidad que establece el Alto Tribunal Alemán, supone una flexibilidad que permite dar cabida a distintos modelos económicos, con ciertos límites ${ }^{21}$.

Tras la Primera Guerra Mundial encontramos que surge el concepto o idea de Constitución económica, y en el segundo conflicto bélico mundial se asentará y desarrollará. En esta etapa es donde vamos a poder encontrar su referencia como un conjunto de preceptos constitucionales con la función de habilitar, orientar y limitar la acción económica del Estado, definiéndola como conjunto de normas básicas destinadas a proporcionar el marco jurídico fundamental para el orden y proceso económico ${ }^{22}$. Otros autores entienden la Constitución económica como el conjunto de las disposiciones constitucionales que se refieren a las relaciones económicas ${ }^{23}$. El concepto de Constitución económica es heredero de las Guerras Mundiales, como factor de crecimiento de las naciones en un contexto donde la economía toma un papel preponderante. En esta situación encontramos su definición como un conjunto de preceptos volcados en orientar la acción económica del Estado, en un intento por crear un marco jurídico adecuado para fomentar el desarrollo de la economía.

La modernización política y constitucional fue diversa, transcurriendo por diversos cauces, que tienen una serie de rasgos comunes y definitorios como la organización económica del sistema capitalista y la forma política del Estado liberal ${ }^{24}$. El impulso político y constitucional, que el liberalismo generó en la sociedad de su época, determinó una organización económica

${ }^{21}$ LASA López, A., Constitución económica y derecho al trabajo en la Unión Europea, Editorial Comares, Granada, 2011, p. 7.

${ }^{22}$ Cancio Meliá, J., «La Constitución Económica...», op. cit., p. 52.

${ }^{23}$ De Vergottini, G., «La Constitución Económica Italiana: Pasado y actualidad», Revista Teoría y Realidad Constitucional, $n .^{\circ}$ 29, UNED, 2012, p. 340.

${ }^{24}$ Bassols Coma, M., Constitución y sistema ..., op. cit., p. 24. 
basada en el sistema capitalista, que además necesitaba la creación de unos pilares políticos necesarios para consolidar su proyección.

Al estudiar la evolución liberal de lo que se definirá como la Constitución económica, debemos tener en cuenta algunos factores. Así es necesario apoyarse en la correspondencia estructural del sistema de economía de mercado y el de derecho privado, una correspondencia que puede ser la base de una Constitución económica ${ }^{25}$. En un primer momento, el sistema de economía de mercado se alimentó del propio sistema de derecho privado, que permitió relanzar el concepto de propiedad privada con una proyección mayor que la que habían obtenido en los primeros textos constitucionales o, al menos, que se acercaba más al valor que a esos derechos quería otorgarle la sociedad, dentro de un sistema de economía de mercado.

Las estructuras constitucionales están desprovistas de todo contenido informador, reflejando exclusivamente la organización de los poderes públicos y el estatuto de las libertades públicas. En este sentido, para caracterizar el constitucionalismo económico de la época, debemos atender a la fórmula tipológica del Estado liberal y sus elementos en el orden social y económico. Todo esto se traduce en una formulación, que se basa en la delimitación de las funciones estatales y del intervencionismo administrativo en la realidad de los hechos para fortalecer y consolidar la estructura capitalista. Esto implicará la construcción de infraestructuras, fomento del industrialismo, proteccionismo aduanero y fiscal, además de la creación de servicios educativos y asistenciale ${ }^{26}$. Aunque el desarrollo constitucional se encuentra en la época liberal en un momento de gestación de las estructuras, que en años posteriores se consolidarán, no por ello debemos desmerecer los logros de las primeras constituciones. Si bien es cierto que, en muchos postulados, son más auténticas declaraciones de principios que el concepto contemporáneo que tenemos de los textos constitucionales, no es menos cierto que también supusieron el planteamiento normativo de futuras estructuras de regulación. En esta temprana época podemos advertir los intentos por organizar los poderes públicos, y una construcción basada en la delimitación de funciones estatales y la necesidad de fomentar el intervencionismo administrativo, si se quiere consolidar el modelo económico.

Uno de los aspectos que más contradicciones puede generar en las primeras formulaciones del Estado liberal, reside en sus propias limitaciones. El liberalismo transige en que el Estado asuma determinados cometidos en el orden económico y social, y no será hasta la Primera Postguerra Mundial cuando asistiremos a la proclamación de los Derechos sociales, y a las valo-

\footnotetext{
${ }^{25}$ MestmäCKeR, E-J, «Poder, Derecho y Constitución...», op. cit., p. 128.

${ }^{26}$ Bassols Coma, M., Constitución y sistema ..., op. cit., pp. 24-25.
} 
raciones constitucionales del orden económico ${ }^{27}$. Hemos de señalar que el Estado liberal se verá envuelto en contradicciones que limitan su fondo de actuación, y que retrasará hasta el periodo de entreguerras la perpetración de un constitucionalismo basado en protección de los Derechos sociales y la conformación de una base económica en su articulado.

\section{EL SISTEMA ECONÓMICO EN EL DEBATE CONSTITUCIONAL}

El debate constitucional está abierto a importantes interpretaciones cuando abordamos el estudio del sistema económico. Así, debemos señalar que el Derecho toma referencia de las relaciones económicas, deduciendo de ellas elementos importantes para la satisfacción de reglas. Su interrelación, el reconocimiento de la acción libre o la necesidad de establecer restricciones, deben estar gobernados por patrones legales mediante la legislación y la interpretación de reglas ${ }^{28}$. Esto significa que operar en el sistema económico, a través del derecho, implica crear unas reglas que regulen el sistema mediante textos legales. De ahí, se infiere que, si en un primer momento hablamos de principios liberales, el derecho creará todo un marco constitucional donde poder acoger el articulado referente a las cuestiones económicas.

En la evolución y extensión del liberalismo a las estructuras económicas de los diferentes países debemos atender a una serie de elementos que gestaron su desarrollo. En el liberalismo anglosajón de EE.UU e Inglaterra, no será hasta la Primera Guerra Mundial y la Gran Depresión, donde se apelará al intervencionismo estatal, manteniendo los caracteres puros de la economía de mercado. Sin embargo, en el resto de las naciones observamos cómo se utilizará el poder político estatal para el desarrollo del sistema capitalista como un elemento necesario en su expansión ${ }^{29}$. El nuevo consenso económico-constitucional de finales del siglo XIX, intensificado tras la Primera Guerra Mundial, desarrolla un Estado que, utilizando parcialmente las propuestas teóricas social-liberales, expande sus funciones públicas hacia una evolución intervencionista $^{30}$. La proyección del Estado liberal a los sistemas económicos nacionales tuvo una concepción diferente en los países. Así podemos ver como en los territorios anglosajones, no se empezará a comprender la necesidad del apoyo de los Estados para superar las graves consecuencias de la Primera Guerra Mundial y las crisis del momento. Es en esos días de desesperación para las clases sociales, se comprueba como el Estado debe conver-

27 Bassols Coma, M., Constitución y sistema ..., op. cit., p. 26.

28 Mestmäcker, E-J., «Poder, Derecho y Constitución...», op. cit., p. 129.

29 Bassols Coma, M., Constitución y sistema ..., op. cit., p. 25.

${ }^{30}$ SAnZ ArCega, E., «Los consensos económicos-constitucionales...», op. cit., p. 7. 
tirse en un factor de crecimiento para la economía, aplicando nuevas políticas que permitan el desarrollo de los países.

Uno de los aspectos a tener en cuenta en esta investigación es la necesidad de distinguir lo que es la Constitución económica liberal. Así podemos definirla por un carácter implícito, que pertenece a la esfera de la sociedad y que, por tanto, no necesita de la constitucionalización expresa del sistema económico, sino que basta simplemente con garantizar la libertad negativa de los individuos a la propiedad y a la libre elección de oficio. Frente a ello podemos oponer la Constitución económica del Estado social, entendida más como una forma de someter el poder económico al poder político o democrático $^{31}$. De hecho, observamos como la Constitución económica liberal dota de libertad al individuo para decidir su destino pero sin una expresa constitucionalización del sistema económico, es decir sin que un exceso de técnica normativa obligue a legislar sobre todo el proceso económico o productivo.

En los países mediterráneos como Italia o España las oligarquías agroindustriales demandarán del Estado la necesidad de impulsar su débil industrialización. Otros países como esa Francia postrevolucionaria necesitará consolidar un modelo liberal político, con la supervivencia de una Administración centralista y autoritaria, que le permita construir la idea de «interés público» en el desarrollo de las actividades económicas privadas. Frente a ello los países germánicos, carentes de una burguesía liberal emprendedora, promocionarán el apoyo político para la construcción de una economía nacional, que impulse la industrialización sobre la base del proteccionismo y la concentración empresarial ${ }^{32}$. La Gran Depresión del XIX supuso el fin de la fe en la economía sin intervención, que presidía el consenso económico-constitucional durante el liberalismo clásico ${ }^{33}$. Algunos países europeos encontrarán en el Estado el elemento para revitalizar sus maltrechas economías, determinando un modelo liberal político, que fomente la actividad privada y emprendedora. Es en estos momentos donde el apoyo político empezará a ser decisivo para crear riqueza en un país, y eso hará necesario también un cambio en los sistemas políticos, avecinando transformaciones en las estructuras socio económicas.

En este análisis no podemos tomar en un sentido estricto el término «liberalizar» entendido como «desregular». Más bien las liberalizaciones comportan el sometimiento de las actividades económicas a una regulación pública pero con el claro objetivo de tutelar y promover la competencia ${ }^{34}$. La ley que protege a la competencia de las restricciones a ella, incorpora ciertos

${ }^{31}$ CAncio Meliá, J., «La Constitución Económica...», op. cit., p. 52.

32 Bassols Coma, M., Constitución y sistema ..., op. cit., pp. 25.

33 SAnZ ArcegA, E., «Los consensos económicos-constitucionales...», op. cit., p. 13.

${ }^{34}$ De Vergottini, G., «La Constitución Económica Italiana...», op. cit., p. 346. 
efectos autorreguladores de la competencia, en la medida en que ellos garantizan libertad de elección a los consumidores, limitan la libertad de acción de los competidores y coordinan decisiones independientes ${ }^{35}$. Es por ello que cuando el Estado liberal busca ese consenso con el concepto de Constitución económica, lo que pretende es crear un campo de actuación con una mínima regulación que además estimule la libre competencia.

En la evolución y conformación del Estado liberal, encontraremos que el intervencionismo administrativo, se convertirá en una manifestación real de su «Constitución económica material», aunque en estos primeros momentos carentes de un constitucionalismo con principios informadores en el orden económico y social ${ }^{36}$. No podemos obviar que, cuando utilizamos el concepto de «Constitución» o «constituyente», pretendemos dotar de trascendencia a esa coyuntura temporal, pues indica que los juristas están fraguando decisiones básicas para la convivencia humana de la sociedad, incidiendo en lo que se ha denominado como "Constitución material», es decir la esencia básica que opera en un modelo de convivencia política ordenada por el Derecho $^{37}$. Esto nos permite señalar que las Constituciones, como herederas de su tiempo, serán objeto de transformaciones y adaptaciones a la realidad del momento histórico en el que se gestan. Y todo ello implicará que los propios textos constitucionales presten, en su evolución, mayor atención a los aspectos económicos y a las garantías constitucionales.

No hay que olvidar, que el constitucionalismo sufrió una serie de transformaciones como consecuencia de los cambios políticos que supone la Primera Guerra Mundial. Las Constituciones evolucionan en su contenido como en el espíritu que las había gestado, lo que supuso que, en el periodo liberal, el orden económico y social fuera una realidad extraconstitucional ${ }^{38}$. En el Estado liberal debemos destacar la labor de los juristas por crear una serie de ideales, que el constitucionalismo posterior desarrollará como verdaderos derechos. El liberalismo estaba dotado de utopía, de un espíritu creador que significaba más en la intención de desarrollar legislativamente conceptos filosóficos, que una realidad positivista materializada en verdaderas garantías. Ese déficit evolutivo implica que el orden económico y social fuera más una aspiración constitucional a tener en cuenta, que una verdadera realidad.

En este contexto debemos destaca que una parte de la doctrina ha definido la Constitución económica como el marco jurídico fundamental, dentro de la estructura y funcionamiento de la actividad económica. Sin embargo, como

${ }^{35}$ MeSTMÄCKER, E-J., «Poder, Derecho y Constitución...», op. cit., p. 129.

${ }^{36}$ Bassols Coma, M., Constitución y sistema ..., op. cit., p. 26.

37 Granado Hijelmo, I., Reflexiones jurídicas para un tiempo de crisis, Ediciones Internacionales Universitarias, Barcelona, 1997, p. 21.

${ }^{38}$ Bassols Coma, M., Constitución y sistema ..., op. cit., p. 26. 
establecen más acertadamente otros sectores doctrinales la Constitución económica se entenderá por un lado como «el conjunto de normas referidas directa o indirectamente a la economía», y por otro como «preceptos, principios y valores que aparentemente no tendrían que ver con la economía, pero que influyen poderosamente en la misma $\rangle^{39}$. Esta última referencia mucho más completa desde el punto de estudio de configuración de la Constitución económica nos aporta una dinámica mayor de estudio. No podemos ceñir el estudio de la Constitución económica como un proceso de análisis de la estructura y funcionamiento de la economía en un contexto jurídico, ya que adolecería de un defecto formal en su estudio al no abarcar todo el espectro que realmente genera. Sin embargo, es más acertado entenderla desde un concepto más aperturista, en el que junto a ese estudio normativo, analizamos una serie de preceptos, principios y valores que influyen en la economía. $\mathrm{Y}$ en esa esencia es donde podemos encontrar algunos de elementos que inspiran propiamente la Constitución económica liberal.

Los nuevos Estados gestaron unas estructuras constitucionales en el que el factor económico social pasa a tener un especial protagonismo. De estas circunstancias históricas surgirá el concepto de «Constitución económica», como una realidad sustantiva e ideológica concurrente con la idea tradicional de Constitución, pasando a denominarse como «Constitución política» ${ }^{40}$. La gestión económica y la participación social en los textos constitucionales adquieren un mayor impulso, como consecuencia del periodo bélico, que produjo una serie de cambios de gran transcendencia en la mentalidad de la época. Eso implicará una serie de elementos que tomarán forma en el nuevo concepto de «Constitución económica».

Pese a todo y en el avance del tiempo, no hay que obviar que el declive de la Constitución económica del Estado social se manifestó en el abandono fáctico que expresó las intenciones socializantes que contenían las Constituciones europeas de la Segunda Postguerra Mundial, y también en los límites constitucionales que querían limitar la capacidad de endeudamiento de los poderes públicos ${ }^{41}$. Es por ello que se hace necesario un estudio revisionista de los contenidos de los textos constitucionales, cuyas nuevas necesidades implicaron una caída de las aspiraciones de la Constitución económica del Estado social.

En la Constitución económica reside una forma de control del poder. El objetivo del Derecho es establecer una regulación económica descentralizada que complete el comportamiento empresarial. Esto nos permite delinear la peculiaridad metodológica de la Constitución económica, permitiendo desa-

${ }^{39}$ García Guerrero, J. L., «Integración económica y reforma...», op. cit., p. 137.

40 Bassols Coma, M., Constitución y sistema ..., op. cit., p. 26.

${ }^{41}$ Cancio Meliá, J., «La Constitución Económica...», op. cit., p. 53. 
rrollar soluciones de política económica que contienen reglas legales y constitucionales ${ }^{42}$. El Derecho actúa como un parámetro de control del ejercicio del poder, a través de una regulación que aporte las líneas mínimas de actuación legal donde enmarcar la política económica.

El establecimiento de límites rígidos a la discrecionalidad política, con la consiguiente fórmula que coarta la democracia, establecerá nuevos parámetros normativos, que abrirá el debate a un replanteamiento de la influencia económica del mercado ${ }^{43}$. Las reglas naturales del mercado van a establecer límites en la discrecionalidad política, y eso implicará nuevas regulaciones, que evolucionen con el tiempo, determinando un control constitucional, que servirá para evitar déficits y endeudamientos excesivos por parte de los Gobiernos.

\section{ELEMENTOS DIFERENCIADORES DE LA CONSTITUCIÓN ECONÓMICA LIBERAL Y LA CONSTITUCIÓN ECONÓMICA SOCIAL. EL DERECHO DE PROPIEDAD PRIVADA Y LA LIBERTAD DE EMPRESA}

El estudio de la Constitución económica liberal nos lleva a reducir el papel del Estado a un mero instrumento que garantiza la igualdad en el ejercicio de la actividad económica, la libertad de circulación y la ausencia de perturbaciones externas e internas. Además, hay que destacar que, indirectamente también se protege a la Sociedad Civil, a través de la garantía institucional de mercado y los derechos fundamentales a la propiedad privada y a la libertad de empresa ${ }^{44}$. Para la Constitución económica liberal es determinante que la actividad económica se haga en condiciones igualitarias sin ningún factor externo o interno, que pueda altera esa libre competencia. Eso va a permitir reforzar el papel de la propiedad privada y la libertad de empresa como derechos que sirven para consolidar el libre mercado.

Frente a la Constitución económica liberal podemos señalar que posteriormente surgieron nuevos movimientos que cuestionaban estas tesis. Así, la nueva forma de Estado social fue consecuencia de la ruptura del principio liberal de separación de las esferas de la política y la economía. Esta situación supuso cambios importantes entre los que podemos destacar la vincula-

${ }^{42}$ MeSTMÄCKeR, E-J., «Poder, Derecho y Constitución...», op. cit., p. 130.

${ }^{43}$ Cancio Meliá, J., «La Constitución Económica...», op. cit., p. 54.

${ }^{44}$ García Guerrero, J. L., «Las integraciones económicas supraestatales y los acuerdos entre bloques económicos, en definitiva, la globalización como último embate al concepto racional normativo de Constitución», en VV. AA: Constitución, Justicia Constitucional y Derecho Procesal Constitucional, Edita Instituto Dominicano de Derecho Constitucional, República Dominicana, 2014, p. 551. 
ción de la Constitución económica al Estado social. Todo ello significa que, de conformidad con esta doctrina, la Constitución económica del Estado social tiene su fundamento legitimador en la preeminencia normativa de las disposiciones referidas a la forma del Estado, traducidas en la configuración del Estado social como la decisión constitucional fundamental, que impone una relación de funcionalidad, y un vínculo social como fuente de definición y limite al mercado ${ }^{45}$. Frente al liberalismo, que impulsaba el individuo y promulgaba una separación entre economía y política, debemos ver las transformaciones, que implica la Constitución económica social, en la que se establecen unas nuevas bases y un modelo de constitucionalismo diferente.

En este análisis debemos tener en cuenta que en las Constituciones del periodo de entreguerras no se regulaban como derechos inviolables, la propiedad e iniciativa económica como en las Constituciones burguesas del siglo XIX. Por un lado, existían cierto favor o preferencia por la propiedad e iniciativa económica pública y al mismo tiempo unos elementos condicionantes de la iniciativa privada. A pesar de la existencia de residuos de los principios básicos del liberalismo, aparece esa orientación en diversas cláusulas constitucionales ${ }^{46}$. De alguna manera en esos incipientes textos constitucionales de los periodos posteriores a las Guerras Mundiales, observamos una temprana tendencia a buscar el apoyo público en la iniciativa privada, superando reminiscencias del liberalismo.

Cuando hablamos de medios de producción debemos tener en cuenta que nos encontramos con un reconocimiento de la propiedad, que conlleva la libre iniciativa privada ${ }^{47}$. El reconocimiento de la propiedad privada está íntimamente ligado a los medios de producción, de ahí que el intervencionismo de los poderes públicos debe ser el mínimo, tan solo para garantizar cierto ámbito de protección constitucional que permita el desarrollo de esa iniciativa privada en libertad.

De este modo, la propiedad individual tiene como límite los intereses generales de la comunidad ciudadana y los sectoriales de los que participan en hacerla productiva. Así, mientras el Estado tradicional se sustentaba en la justicia conmutativa, el Estado social se mantenía en una justicia distributiva, es decir mientras que uno era fundamentalmente un Estado legislativo el otro es un Estado gestor cuyas condiciones deben someterse las modalidades de legislación ${ }^{48}$. Por tanto, no es posible hablar de un concepto de propiedad que no tenga ciertos límites, pues la seguridad jurídica que puede ofrecer el Estado precisamente reside en un sometimiento a la legislación.

${ }^{45}$ Lasa López, A., Constitución económica y derecho..., op. cit., p. 4.

46 De Vergottini, G., «La Constitución Económica Italiana...», op. cit., p. 340.

${ }^{47}$ García Guerrero, J. L., «Integración económica y reforma...», op. cit., p. 137.

${ }^{48}$ García-Pelayo, M., Las transformaciones del Estado..., op. cit., p. 26. 
También se debe señalar que el reconocimiento de la propiedad privada se extiende a los medios de producción. La libertad de empresa conlleva la libertad de iniciativa privada, que deben ser inmunes a la acción de los poderes públicos y además respetar el contenido esencial de esos derechos ${ }^{49}$. No podemos hablar de libre mercado sino respetamos los contenidos básicos del derecho a la propiedad privada y la libertad de empresa. Esto permite crear un clima adecuado para el desarrollo de la actividad económica e impulsar las acciones necesarias para su consolidación, según argumenta la filosofía liberal.

El liberalismo propugna una economía de mercado no capitalista, compuesta de productores independientes o empresas autogestionadas. Se trata de un sistema basado en la propiedad privada y en la cual las decisiones de producción se hacen por iniciativas descentralizadas de los agentes económicos. Lógicamente para que este sistema funcione es necesario la búsqueda del interés personal ${ }^{50}$. Es por ello que las revoluciones liberales supusieron ese impulso para garantizar la búsqueda de ese interés personal, con un claro exponente en el crecimiento de la burguesía y el desarrollo de los derechos del individuo en los primeros textos constitucionales.

Hay que recordar que en la temprana Declaración de Derechos del Hombre y el Ciudadano de 1789 se consagró el derecho de propiedad privada como «un derecho inviolable y sagrado». Sin embargo, esa caracterización propia de los movimientos revolucionarios no puede encajar en la evolución posterior donde el derecho de propiedad se ha transformado internamente por su funcionalización en la realización del interés general y la libertad de empresa. De hecho, las reglas de la función de los poderes públicos se observa desde dos perspectivas, es decir por un lado la actividad de ordenación del mercado y la disciplina de la competencia en su seno como garantía de su correcto funcionamiento, y por otro la actividad de producción de bienes como una actividad industrial en mano pública ${ }^{51}$. El desarrollo original que las revoluciones liberales impregnaron a los textos constitucionales o a las primeras Declaraciones de Derecho nada tiene que ver con la evolución que posteriormente se asigna a esos tempranos conceptos jurídicos. Un ejemplo de ello es la evolución de los términos propiedad privada en virtud del cual pasó de ser un derecho inviolable a convertirse en un factor integrante en la libertad de empresa.

El pensamiento liberal ha cuestionado los referentes sociológicos y políticos, aunque siempre ha destacado la libertad para ejercer una profesión, así

49 García Guerrero, J. L., «Las integraciones económicas supraestatales y los acuerdos entre bloques económicos...», op. cit., p. 552.

${ }^{50}$ De Vroey, M., «El liberalismo económico...», op. cit., p. 14.

${ }^{51}$ Garcia Llovet, E., «Constitución económica...», op. cit., p. 125. 
como la libertad para comerciar, enajenar la capacidad de trabajo y desarrollar a la joven burguesía. Y precisamente en esa remoción de obstáculos a la libertad del individuo, será donde podamos encontrar las bases del liberalis$\mathrm{mo}^{52}$. El encuentro de la ideología liberal permite desarrollar al individuo y por tanto a los factores económicos que le rodean, de ahí se infiere el gran impulso que, a partir de esos momentos, alcanzará la burguesía.

Para hablar propiamente de un reconocimiento de la libertad privada se debe ejercer dentro de un contexto inmune a la acción de los poderes públicos. La actuación de intervención de dichos poderes debe ser muy restringida, con medidas destinadas a compatibilizar ese ejercicio que respeta los derechos de libertad privada con otros derechos o bienes constitucionales, dotados de protección ${ }^{53}$. El crecimiento de esos factores de la libertad privada exige una actuación muy definida de los poderes públicos, con objeto de no limitar el contenido esencial de ese libre crecimiento. Y esa aspiración tan sólo se consigue otorgando un régimen jurídico, es decir un marco legal en el que poder dotar de protección legislativa y constitucional que permita asegurar el disfrute de dicho derecho por múltiples titulares.

Es llamativo comprobar como el Derecho comunitario ha concurrido a la revalorización de los componentes de la Constitución originaria inspirado en los principios liberales, que habían sido difuminados por las lecturas en clave socialista, que había realizado la legislación y la jurisprudencia ${ }^{54}$. Los principios liberales han inspirado los textos constitucionales y en esa esencia hemos determinado la fuente que ha permitido relanzar otras especializaciones jurídicas como el Derecho comunitario. Es por tanto de vital importancia no negar el beneficio implícito que la Constitución económica liberal desarrolló en las futuras generaciones como inspirador de un modelo dotado de garantías.

Los ámbitos de libertad privados, son inmunes a la acción de los poderes públicos. Esto exige a dichos poderes un esfuerzo para respetar el contenido esencial de los derechos de libertad de que gozan los titulares ${ }^{55}$. Hemos de destacar que desde los años 70 y tras la catástrofe de las dos Guerras Mundiales, se ha vuelto a recoger postulados del liberalismo a través del capitalismo en lo que se conoce como neoliberalismo. En este sentido y dentro del devenir de los acontecimientos podemos señalar que las élites sociales, cansadas del control social de las actividades económicas y de la extensión de la propiedad pública, se han revelado. Esto ha supuesto revitalizar la vieja utopía

52 Carvajal Baeza, R., «Liberalismo, democracia y ordenamiento territorial», Cuadernos de Administración, vol. 15, n. ${ }^{\circ} 22,1996$, p. 126.

${ }^{53}$ García Guerrero, J. L., «Integración económica y reforma...», op. cit., p. 137.

${ }^{54}$ De Vergottini, G., «La Constitución Económica Italiana...», op. cit., p. 345.

55 García Guerrero, J. L., «Integración económica y reforma...», op. cit., p. 137. 
liberal de situar el mercado en el centro de la sociedad y subordinar las instituciones políticas a las leyes del mercado ${ }^{56}$. El liberalismo volvió a tomar sentido, a pesar de las críticas recibidas, tras los desastres humanos de las Guerras Mundiales, porque en los postulados liberales sobre un mercado sin restricciones en el fondo se determinaba una forma de impulsar el desarrollo de la nación, a expensas del control del poder sobre la economía.

Por otro lado, no podemos obviar que la penetrante regulación pública de la economía es coherente con la liberalización. Así, podemos destacar que liberalizar es derogar las disposiciones que limitan o impiden la competencia como aquellas que subordinan el desarrollo de la actividad a la expedición de medidas administrativas o un hecho equivalente como el silencio positivo ${ }^{57}$. Liberalizar implica desarrollar una serie de actividades que, en definitiva, permiten el crecimiento de la actividad económica evitando aquellas medidas que coarten su avance.

Hay que tener en cuenta que el reconocimiento de la propiedad privada se extiende a los medios de producción ${ }^{58}$, esto significa que nos encontramos ante una forma de reconocer la libertad de empresa. A pesar de que autores como Marx, Durkheim o Weber, entre otros, realizaron una contundente crítica a la economía de mercado y al liberalismo económico, contribuyendo así a cambiar el rumbo de la organización política y los sistemas económicos, no podemos negar que la economía política liberal estructuró las relaciones sociales y políticas de la modernidad ${ }^{59}$. Por ello, debemos destacar el valor del liberalismo en la articulación de las relaciones sociales y políticas, dentro de un contexto en el que subyace la economía como elemento de evolución de la sociedad.

\section{VALORACIONES FINALES}

La Constitución económica del modelo liberal proclamaba la rígida separación entre Estado y sociedad, es decir, la intervención estatal se reduce a su mínima actuación, estableciéndose una garantía institucional del mercado. Además, los poderes públicos deben de garantizar que el mercado funcione en condiciones de economicidad, asegurando la igualdad de los agentes económicos y la libre competencia de los mismos. Eso significa que las decisio-

${ }^{56}$ De Castro, C.; Pedreño, A., «La Gran Restauración: sociología económica de la crisis global y actualidad de la crítica de Karl Polanyi al liberalismo económico». Áreas. Revista Internacional de Ciencias Sociales, n. $^{\circ}$ 31, 2012, p. 5.

57 De Vergottini, G., «La Constitución Económica Italiana...», op. cit., p. 345.

58 García Guerrero, J. L., «Integración económica y reforma...», op. cit., p. 137.

59 De Castro, C.; Pedreño, A., «La Gran Restauración: sociología económica de la crisis global...», op. cit., p. 6. 
nes de las unidades económicas no deben basarse en decisiones de los poderes públicos sino que estarán orientadas al beneficio económico. El mercado a través de la oferta y la demanda determina el comportamiento económico ${ }^{60}$. No hay que olvidar que el Estado liberal en sus diferentes niveles adoleció de los recursos y la voluntad política necesaria para crear una red de protección social ${ }^{61}$. En el contexto liberal se proclama la separación Estado y sociedad, y se establecen unas normas de regulación del mercado sin apenas intervención estatal. Según esta filosofía los flujos económicos no los tienen los poderes públicos sino que viene determinado por la oferta y demanda de las unidades económicas, en un claro ejercicio de la libre competencia.

Cuando hablamos de la influencia de la Constitución económica liberal en la formulación de las estructuras económicas de un país, debemos tener en cuenta que a los poderes públicos y especialmente al legislativo se les exige que garanticen que el mercado funcione en igualdad entre todos los agentes, garantizando la libre competencia de los mismos. Esto implica que el mercado funcione en condiciones de economicidad, pero también debemos tener en cuenta que su comportamiento no puede basarse en decisiones de los poderes públicos, sino que buscarán el beneficio económico a través de la oferta y la demanda ${ }^{62}$. Esto significa que el mercado se basa en una serie de reglas propias del capitalismo, en la que la intervención de los poderes públicos será más el de un regulador operativo que garantice un correcto funcionamiento del mercado. Para que ese mercado funcione con regularidad es importante garantizar una igualdad entre todos los actores económicos, entendidos como los sujetos activos que mueven la economía de un país. Por tanto, el poder legislativo deberá crear una atmósfera normativa que permita el crecimiento económico, pero sin mayor intervencionismo ya que de lo contrario, una actuación de los poderes públicos en beneficio de determinados intereses podría viciar el sistema de crecimiento y sería desigual, provocando competencia desleal.

El estudio de la literatura económica nos arroja un indubitado consenso acerca de la superioridad del sistema de mercado, frente a otras formas alternativas de organización económica. Esto supone que haya sectores que motivan la intervención del Estado para proporcionar una mejora del bienestar, frente a otras posturas que consideran que el Estado no debe expandirse más allá de una estructura mínima ${ }^{63}$. La supremacía del mercado determinará las

${ }^{60}$ García Guerrero, J. L., «Las integraciones económicas supraestatales...», op. cit., p. 551.

${ }^{61}$ Esteban De Vega, M., «La asistencia liberal en la España de la Restauración», Revista de la Historia de la Economía y de la Empresa, $n .^{\circ}$ 4, 2010, p. 52.

${ }^{62}$ García Guerrero, J. L., «Integración económica y reforma...», op. cit., p. 136.

${ }^{63}$ SAnZ ArCEGA, E., «Los consensos económicos-constitucionales...», op. cit., p. 8. 
relaciones entre el Estado y la sociedad, marcando los límites de su intervención, bien para crear un contexto jurídico en el que desarrollarse o simplemente con la intención de promover una intervención más activa en el comportamiento de los agentes económicos.

Los posicionamientos liberales mantienen la unidad económica nacional y la unidad de mercado, que implica la libertad de circulación de capitales, servicio y mano de obra. Así mismo se plasma la igualdad en las condiciones básicas de ejercicio de la actividad económica. Esto determina que la garantía institucional del mercado conlleva que los poderes públicos $\mathrm{y}$, en concreto, el poder legislativo respeten una serie de instituciones o figuras de derecho privado. Lo que nos lleva a mantener que la legislación en su intervención reguladora no puede ni debe desfigurar los contenidos esenciales del merca$\mathrm{do}^{64}$. El poder legislativo se somete a los intereses del mercado en un intento por garantizar esa libertad de circulación de capitales y servicios. El mercado se regula por sus propias normas intrínsecas y es por ello que, para garantizar las condiciones de ejercicio de la actividad económica, se deban respetar sus condiciones de funcionamiento.

La doctrina liberal, desde el momento que distingue entre Estado y Sociedad Civil, asume el desenvolvimiento del hombre como ciudadano en el Estado e individuo de la sociedad. Eso significa que solo la propiedad, entendida como un derecho civil natural, hace a los hombres capaces de los derechos políticos $^{65}$. El hombre se desarrolla como ciudadano dentro de la estructura del Estado, y será allí donde empiece a crecer como ente dotado de derechos. Una formulación en la que subyace el concepto de dominio o propiedad, que implícitamente suscita la presencia de derechos o principios económicos.

Hay que concluir que desde la teoría política-constitucional europea, el consenso económico-constitucional liberal, inspirado en el pensamiento de la corriente liberal hegemónica durante la mayor parte del siglo XIX, defendía la libertad sobre la igualdad, considerando el mercado como fuente de riqueza. Por ello, las declaraciones de derechos de los textos constitucionales del liberalismo clásico sancionan explícitamente el derecho de propiedad, apostando por la libertad de empresa ${ }^{66}$. La filosofía liberal hace un desarrollo de la libertad de creación de estructuras empresariales como factor de crecimiento, en un contexto en el que el consenso económico-constitucional-liberal promoverá la liberalización de los mercados. Y precisamente sobre esa

${ }^{64}$ García Guerrero, J. L., «Las integraciones económicas supraestatales...», op. cit., pp. 551-552.

${ }_{65}$ Carvajal Baeza, R., «Liberalismo, democracia y ordenamiento...», op. cit., p. 123.

${ }^{66}$ SAnZ Arcega, Eduardo: «Los consensos económicos-constitucionales...», op. cit., p. 7. 
base, la Constitución económica liberal creará el marco jurídico adecuado para la transformación de una sociedad, dotándola de derechos fundamentales y garantías normativas.

\section{BIBLIOGRAFÍA}

Bassols Coma, M., Constitución y sistema económico, Editorial Tecnos, Madrid, 1985.

Cancio Melié, J., «La Constitución Económica: Promesas Incumplibles», Revista Jurídica de la Universidad Autónoma de Madrid, $n .^{\circ} 7,2002$, pp. 49-101.

CARvajal BAezA, R., «Liberalismo, democracia y ordenamiento territorial», Cuadernos de Administración, vol. 15, $n .^{\circ} 22,1996$, pp. 117-146.

De CAstro, C.; Pedreño, A., «La Gran Restauración: sociología económica de la crisis global y actualidad de la crítica de Karl Polanyi al liberalismo económico», Áreas. Revista Internacional de Ciencias Sociales, $n .{ }^{\circ} 31,2012$, pp. 5-7.

De Vergottini, G., «La Constitución Económica Italiana: Pasado y actualidad», Revista Teoría y Realidad Constitucional, $n .^{\circ}$ 29, UNED, 2012, pp. 339-354.

De VRoey, M., «El liberalismo económico y la crisis», Lecturas de Economía, $n .^{\circ} 70$, 2009, pp. 11-38.

DíAz Revorio, F. J., «Cádiz e Iberoamérica: Sobre las influencias medievales y contemporáneas en la Constitución de $1812 \ldots$ y en Iberoamérica», en VV. AA: $L a$ Constitución de 1812 y su difusión en Iberoamérica, Edita Tirant Lo Blanch, Valencia, 2012.

EsteBAN DE VEGA, M., «La asistencia liberal en la España de la Restauración», Revista de la Historia de la Economía y de la Empresa, $n .^{\circ} 4,2010$, pp. 49-62

GARCÍA GUERRERO, J. L., «Integración económica y reforma constitucional», en VV.AA.: Senado de la República. Visión y análisis comparativo de reformas constitucionales en Iberoamérica, Edita PNUD, Santo Domingo, 2005.

GARCÍA GUERRERO, J. L., «Las integraciones económicas supraestatales y los acuerdos entre bloques económicos, en definitiva, la globalización como último embate al concepto racional normativo de Constitución», en VV. AA.: Constitución, Justicia Constitucional y Derecho Procesal Constitucional, Edita Instituto Dominicano de Derecho Constitucional, República Dominicana, 2014.

GARCIA Llovet, E., «Constitución económica y Constitución territorial económica», Autonomías: Revista Catalana de Derecho Público n. ${ }^{\circ} 22,1997$, pp. 121-154.

García-Pelayo, M., Las transformaciones del Estado contemporáneo, Editorial Alianza, Madrid, 1977.

Granado Hijelmo, I., Reflexiones jurídicas para un tiempo de crisis, Ediciones Internacionales Universitarias, Barcelona, 1997.

HABERMAS, J., Legitimationsprobleme im Spätkapitalismus, Ediciones Catedrá, Madrid, 1973.

LASA López, A., Constitución económica y derecho al trabajo en la Unión Europea, Editorial Comares, Granada, 2011.

MestMÄCKer, E-J., «Poder, Derecho y Constitución Económica», Estudios Públicos, $n .^{\circ} 3,1981$, pp. 122-135. 
PArra, J. F., «Liberalismo: nuevo institucionalismo y cambio político», Política y Cultura, $n .^{\circ} 24,2005$, pp. 31-61.

Rasmussen, H., La Constitución de la Comunidad Económica Europea. Editorial Trivium, Madrid, 1990.

RUIZ JIMÉNEZ, J., «Derechos humanos y estructura socioeconómicas en un régimen constitucional democrático», en VV.AA.: Constitución, economía y regiones. Edita Ibérico Europea de Ediciones, Madrid, 1978.

SANZ ARCEGA, E., «Los consensos económicos-constitucionales: diagnóstico y afanes de la política económica», en Papeles de trabajo del Instituto de Estudios Fiscales. Serie economía, $n .^{\circ} 1,2015$, pp. 1-19.

VV.AA., La Constitución de 1812 y su difusión en Iberoamérica. Edita Tirant Lo Blanch, Valencia, 2012.

- Constitución, Justicia Constitucional y Derecho Procesal Constitucional, Edita Instituto Dominicano de Derecho Constitucional, República Dominicana, 2014.

- Constitución, economía y regiones. Edita Ibérico Europea de Ediciones, Madrid, 1978.

TITLE: The liberal economic Constitution as a guarantee of free market. Private property rights and freedom of enterprise

RESUMEN: La Constitución económica liberal proclamaba la rígida separación entre Estado y sociedad para desarrollar el libre mercado. El debate jurídico implica interpretaciones en el estudio del sistema económico y su proyección como norma. Las Constituciones Europeas se preocupan por definir la libertad como garantía jurídica, una vez superado los desafios de las Guerras Mundiales. En esos momentos surgen derechos como la propiedad privada y la libertad de empresa, que se incorporan a los textos constitucionales contemporáneos. Este artículo analiza la influencia de las revoluciones liberales en la configuración de los derechos económicos.

Palabras ClaVE: Política, Constitución, propiedad, economía, libertad de empresa.

ABSTRACT: The liberal economic constitution proclaimed the rigid separation between State and society to develop the free market. The legal debate involves interpretations in the study of the economic system and its projection as standard. The European Constitutions are concerned with defining freedom as legal guarantee, once overcome the challenges of the World Wars. In those moments arise rights as private property and free enterprise, incorporated to contemporary constitutional texts. This article analyzes the influence of the liberal revolutions in shaping economic rights.

KEY WORDS: Politics, Constitution, property, economy, freedom of company. 